\title{
Optimization and single-laboratory validation of a method for the determination of flavonolignans in milk thistle seeds by high-performance liquid chromatography with ultraviolet detection
}

\author{
Elizabeth Mudge $^{1} \cdot$ Lori Paley $^{1} \cdot$ Andreas Schieber $^{2,3} \cdot$ Paula N. Brown $^{1}$
}

Received: 1 June 2015 /Revised: 14 July 2015 / Accepted: 16 July 2015 / Published online: 31 July 2015

(C) The Author(s) 2015. This article is published with open access at Springerlink.com

\begin{abstract}
Seeds of milk thistle, Silybum marianum (L.) Gaertn., are used for treatment and prevention of liver disorders and were identified as a high priority ingredient requiring a validated analytical method. An AOAC International expert panel reviewed existing methods and made recommendations concerning method optimization prior to validation. A series of extraction and separation studies were undertaken on the selected method for determining flavonolignans from milk thistle seeds and finished products to address the review panel recommendations. Once optimized, a single-laboratory validation study was conducted. The method was assessed for repeatability, accuracy, selectivity, LOD, LOQ, analyte stability, and linearity. Flavonolignan content ranged from 1.40 to $52.86 \%$ in raw materials and dry finished products and ranged from 36.16 to $1570.7 \mu \mathrm{g} / \mathrm{mL}$ in liquid tinctures. Repeatability for the individual flavonolignans in raw materials and finished products ranged from 1.03 to $9.88 \%$ $\mathrm{RSD}_{\mathrm{r}}$, with HorRat values between 0.21 and 1.55. Calibration curves for all flavonolignan concentrations had correlation coefficients of $>99.8 \%$. The LODs for the flavonolignans ranged from 0.20 to $0.48 \mu \mathrm{g} / \mathrm{mL}$ at $288 \mathrm{~nm}$. Based on the results of this single-laboratory validation, this method is suitable for the quantitation of the six major flavonolignans in milk thistle raw
\end{abstract}

Paula N. Brown

paula_brown@bcit.ca

1 Natural Health \& Food Products Research Group, British Columbia Institute of Technology, 3700 Willingdon Avenue, Burnaby, BC V5G 3H2, Canada

2 4-10 Agriculture/Forestry Centre, Department of Agricultural, Food and Nutritional Science, University of Alberta, Edmonton, AB T6G 2P5, Canada

3 Institute of Nutritional and Food Sciences, Chair of Food Technology and Food Biotechnology, University of Bonn, Roemerstrasse 164, D-53117 Bonn, Germany materials and finished products, as well as multicomponent products containing dandelion, schizandra berry, and artichoke extracts. It is recommended that this method be adopted as First Action Official Method status by AOAC International.

Keywords Silybum marianum (L.) Gaertn · Flavonolignans · Silymarins · Dietary supplements · High-performance liquid chromatography $\cdot$ Validation

\section{Introduction}

Herbal dietary supplements, such as milk thistle (Silybum marianum (L.) Gaertn.), have considerable variation due to several factors including the quality of starting materials, process conditions, product formulations, and storage. Therefore, stringent analytical methods to evaluate and confirm product quality for both starting materials and finished products are necessary. Milk thistle supplements have consistently been ranked as a top selling product in the past decade and will likely continue as research accumulates in support of its use as a hepatoprotectant $[1,2]$. The seeds, which are used in herbal preparations, contain the group of components classified as the silymarins, which have been shown to have hepatoprotective, antioxidant, neuroprotective, antidiabetic, and anti-cancer activities [3-11]. The silymarins are composed of the six major flavonolignans: silychristin, silydianin, silybin A, silybin B, isosilybin A, and isosilybin B shown in Fig. 1.

Milk thistle is available in a variety of formulations including capsules, tablets, tinctures, and dry powders, while other formulations such as phytosomes and liposomes have been developed to improve flavonolignan bioavailability $[12,13]$. Products have been enhanced by the addition of several other extracts including schizandra berry, artichoke, and dandelion which may potentially impact flavonolignan quantitation. Traditionally, flavonolignans 
Fig. 1 Structure of silychristin (1), silydianin (2), silybin A (3), silybin B (4), isosilybin A (5), and isosilybin $\mathrm{B}(6)$<smiles>COc1cc([C@H]2Oc3c(O)cc([C@@H]4Oc5cc(O)cc(O)c5C(=O)[C@H]4O)cc3[C@@H]2CO)ccc1O</smiles><smiles>COc1ccccc1O</smiles>

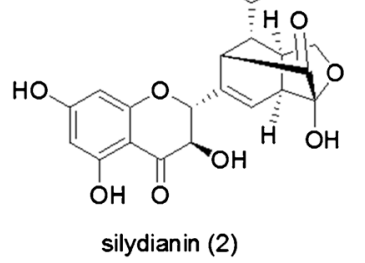<smiles>COc1cc([C@H]2Oc3cc([C@@H]4Oc5cc(O)cc(O)c5C(=O)[C@H]4O)ccc3O[C@H]2CO)ccc1O</smiles><smiles>COc1cc([C@H]2Oc3cc([C@@H]4Oc5cc(O)cc(O)c5C(=O)[C@H]4O)ccc3O[C@H]2CO)ccc1O</smiles><smiles>COc1cc([C@H]2Oc3ccc([C@@H]4Oc5cc(O)cc(O)c5C(=O)C4O)cc3OC2CO)ccc1O</smiles><smiles>COc1cc([C@H]2Oc3ccc([C@@H]4Oc5cc(O)cc(O)c5C(=O)C4O)cc3O[C@H]2CO)ccc1O</smiles>

are determined using HPLC-UV with phosphoric acid in the mobile phase, which excludes the ability to couple the analyses for mass spectrometric detection [14-16]. A growing trend for methods using UPLC and other higher pressure LC systems for separation of flavonolignans has recently occurred, which reduces analysis time and overall solvent usage [17]. As the incorporation of such methods would require many herbal product manufacturers to purchase these new and expensive instruments, they may not be suitable for ubiquitous product quality analysis of milk thistle. Another method that manufacturers use to reduce analysis time is with a non-specific spectrometric method for quantifying total silymarin content, which may lead to erroneous values as many components in the extract may absorb at the specified wavelength.

Clinical evidence of milk thistle efficacy as a hepatoprotectant and in the treatment of liver damage, disease, and cirrhosis has been inconclusive [18-23]. Meta-analyses have pointed out several flaws in study designs including the lack of chemical characterization of products evaluated and the variable dosages administered. To further complicate milk thistle research, clinical trials refer to milk thistle as silibinin, silymarin, or milk thistle, which are all separate entities and are not clearly defined between publications [24]. Inclusion of chemical characterization of products used in milk thistle research is essential in order to evaluate its effectiveness and may lead to more conclusive findings. Therefore, it is essential to develop fast, reliable, precise, accurate, and validated methods for individual flavonolignans in milk thistle raw materials and products.
Milk thistle has been classified as a high priority dietary supplement requiring a validated method for quantifying flavonolignan content. In 2009, an AOAC Expert Review Panel (ERP) convened to evaluate methods submitted for milk thistle quantitation and determined the INA method 115.00 Silymarins in milk thistle by HPLC was suitable; provided several modifications are evaluated prior to validation [15, 25]. The ERP recommended several modifications to the original method. This method involved defatting of the milk thistle seeds for several hours using a Soxhlet extractor, followed by an overnight methanol Soxhlet extraction of the flavonolignans [15]. One recommendation of the ERP was to evaluate the necessity of the defatting step and also to adapt the method for multiple matrices. Other recommendations included evaluating mobile phases compatible with both ultraviolet and mass spectrometric detectors and improving the chromatographic separation [25].

The objectives of this work were to address the modifications suggested by the ERP on milk thistle method optimization by using statistically guided optimization procedures. Several extraction parameters were evaluated including pretreatment volume, contact time, and extraction method. The optimized method for flavonolignans in milk thistle was subjected to a single-laboratory validation according to AOAC International guidelines [26]. The method quantifies the six major flavonolignans in several matrixes including raw milk thistle seeds, bulk extract, single and multi-component capsules, tablets, and tinctures. 


\section{Experimental}

\section{Reagents and reference materials}

HPLC grade methanol was purchased from VWR International (Mississauga, ON, Canada). HPLC grade hexane and ACS grade formic acid and sulfuric acid were purchased from Fisher Scientific (Ottawa, ON, Canada). Water was deionized using a Barnstead water purification system from Fischer Scientific and further filtered through $0.22 \mu \mathrm{m}$ nylon filters. The high-purity certified reference materials silybin A, silybin B, silychristin, silydianin, isosilybin A, and isosilybin B were purchased from Cerilliant Corporation (Round Rock, TX). A silybin A/B combination standard was provided from Chromadex (Irvine, CA). All standards were stored in a desiccator at $-20{ }^{\circ} \mathrm{C}$ for long-term storage.

\section{Purity assessment of reference materials}

To confirm purity, quantitative NMR (qNMR) was performed on the individual flavonolignan reference standards using a Varian Mercury VX spectrometer operating at $400.13 \mathrm{MHz}$ for ${ }^{1} \mathrm{H}$. Samples were dissolved in deuterated DMSO and analyzed by standard proton NMR spectrometry for identification and qNMR for quantitative analysis according to Pauli et al. [27]. The silybin A/B mixture standard was assessed for purity by calibrating the concentrations using the individual flavonolignan standards.

\section{Test materials}

One source of milk thistle seeds was used in the optimization studies. This source was cultivated in 2009 at Midmore Organic Farm (Morinville, AB, Canada) and deposited in the University of Alberta Vascular Plant Herbarium, accession number ALTA 126811, under the supervision of botanist Dorothy Fabijan. Eleven samples were used in the singlelaboratory validation. Two sources of $S$. marianum seeds were obtained from commercial suppliers. The first being the one used in the optimization study and the second was purchased from Horizon Herbs (Williams, OR). A milk thistle powdered extract was provided by Euromed (Monza, Italy). Several commercial products were purchased from local health stores. These include single ingredient milk thistle products and multi-component products with extracts such as schizandra berry, dandelion, and artichoke. The test samples are described in Table 1.

\section{HPLC analysis}

An Agilent 1290 HPLC system equipped with an autosampler, binary pump, and diode array detector (Agilent Technologies, Mississauga, ON, Canada) was used. The separation was achieved on a Kinetex ${ }^{\circledR}$ XB-C18 $2.6 \mu \mathrm{m}, 3.0 \times 100$ mm column (Phenomenex, Torrance, CA). The mobile phase was composed of (a) $0.1 \%$ formic acid in water and (b) $0.1 \%$ formic acid in $80 \%$ aqueous methanol. The flow rate for the separation was $0.4 \mathrm{~mL} / \mathrm{min}$ ( 0 to $36 \mathrm{~min}, 45.1$ to $46 \mathrm{~min}$ ) and $0.45 \mathrm{~mL} / \mathrm{min}$ during the re-equilibration (36.1 to $45 \mathrm{~min}$ ). The gradient elution was as follows: $0-1 \mathrm{~min}: 15 \% \mathrm{~B}$; 1-2 $\mathrm{min}: 15-43 \% \mathrm{~B}$; $2-$ 10 min: 43-45 \%B; 10-25 min: 45-55\%B; 25-27 min: 55$60 \% \mathrm{~B}$; 27-35 min: 60-100\%B; 35-36 min: 60-100\%B; 36$36.1 \mathrm{~min}: 100-15 \% \mathrm{~B} ; 36.1-45 \mathrm{~min}: 15 \% \mathrm{~B}$. The column temperature was $25^{\circ} \mathrm{C}$ and injection volume was $2 \mu \mathrm{L}$. UV spectra were collected from 200 to $400 \mathrm{~nm}$ with $288 \mathrm{~nm}$ used for detecting the flavonolignans. Data was processed using OpenLab software (Agilent Technologies).

\section{Optimization—pretreatment}

Hexane defatting Five $10 \mathrm{~g}$ replicates of ground milk thistle seed were weighed into cellulose extraction thimbles and extracted with $100 \mathrm{~mL}$ of hexane using a Soxhlet apparatus for $6 \mathrm{~h}$. Thimbles were dried at $40{ }^{\circ} \mathrm{C}$ to remove residual solvent.

Sulfuric acid pretreatment Five $4 \mathrm{~g}$ replicates of ground milk thistle seed were weighed into $50 \mathrm{~mL}$ polypropylene tubes and treated with $40 \mathrm{~mL}$ of $1.5 \% \mathrm{v} / \mathrm{v}$ sulfuric acid at $50{ }^{\circ} \mathrm{C}$ in a water bath shaker at $60 \mathrm{rpm}$ for $24 \mathrm{~h}$. After cooling to room temperature, the samples were centrifuged at $5000 \mathrm{rpm}$ for $5 \mathrm{~min}$ and the supernatant was discarded. The solids were recovered and allowed to dry at room temperature for $24 \mathrm{~h}$.

Five $300 \mathrm{mg}$ replicates of control (no pretreatment), hexanetreated, and sulfuric acid-treated material were extracted with $40 \mathrm{~mL}$ methanol for $30 \mathrm{~min}$ using a sonicating bath at $45^{\circ} \mathrm{C}$. After cooling to room temperature, the samples were centrifuged at $5000 \mathrm{rpm}$ for $5 \mathrm{~min}$. The methanol was transferred to a $50-\mathrm{mL}$ volumetric flask and brought up to volume with methanol. An aliquot was placed into an HPLC vial and analyzed for flavonolignan content by HPLC-UV.

Pretreatment contact time Triplicate $200 \mathrm{mg}$ samples of ground milk thistle seeds were extracted with $10 \mathrm{~mL}$ of $1.5 \% \mathrm{H}_{2} \mathrm{SO}_{4}$ in a $50{ }^{\circ} \mathrm{C}$ water bath shaking at $60 \mathrm{rpm}$ for $0.5,1,2,4,6,18$, and $24 \mathrm{~h}$. The samples were cooled and centrifuged at $5000 \mathrm{rpm}$ for $5 \mathrm{~min}$ and the supernatant discarded. Samples were extracted with $25 \mathrm{~mL}$ of methanol and sonicated at $45^{\circ} \mathrm{C}$ for $30 \mathrm{~min}$. They were cooled to room temperature and centrifuged at $5000 \mathrm{rpm}$ for $5 \mathrm{~min}$, and a 1-mL aliquot was analyzed for flavonolignan content by HPLC-UV.

Pretreatment and rinse volume In triplicate, $200 \mathrm{mg}$ samples of ground milk thistle seed were pre-treated with either $10 \mathrm{~mL} 1.5 \% \mathrm{H}_{2} \mathrm{SO}_{4}$ solution or $2 \mathrm{~mL} 1.5 \% w / w \mathrm{H}_{2} \mathrm{SO}_{4}$ 
Table 1 Composition of each test sample subjected to the single-laboratory validation including the dilution required for the samples to be within the calibration range of the method

\begin{tabular}{llll}
\hline Sample code & Sample type & Constituents & Dilution factor \\
\hline MT-RM001 & Raw material & Milk thistle seeds & $\mathrm{n} / \mathrm{d}$ \\
MT-RM002 & Raw material & Milk thistle seeds & $\mathrm{n} / \mathrm{d}$ \\
MT-BE001 & Bulk extract & Milk thistle extract & $1: 5$ \\
MT-CP001 & Hardshell capsule & Milk thistle extract & $1: 10$ \\
MT-CP002 & Hardshell capsule & Milk thistle, schizandra berry & $1: 10$ \\
MT-CP003 & Hardshell capsule & Milk thistle, dandelion, artichoke extract & $1: 10$ \\
MT-TB001 & Tablet & Milk thistle extract, milk thistle seed & $\mathrm{n} / \mathrm{d}$ \\
MT-TB002 & Tablet & Milk thistle extract & $1: 10$ \\
MT-TN001 & Tincture & Milk thistle extract & $1: 5$ \\
MT-TN002 & Tincture & Milk thistle, dandelion extract & $1: 2$ \\
MT-TN003 & Tincture & Milk thistle extract & $1: 5$ \\
\hline
\end{tabular}

$n / d$ no dilution solution for $30 \mathrm{~min}$. Samples were cooled, centrifuged at $5000 \mathrm{rpm}$ for $5 \mathrm{~min}$, and decanted and rinsed by adding either 10 or $2 \mathrm{~mL}$ respectively of deionized water. After vortexing for $30 \mathrm{~s}$, samples were centrifuged at $5000 \mathrm{rpm}$ for $5 \mathrm{~min}$ and the rinse water was discarded. Each sample was extracted with methanol as per the sonication procedure above and analyzed for flavonolignan concentration. These experiments were repeated with the rinse step omitted.

\section{Optimization-extraction}

Soxhlet procedure Five $5 \mathrm{~g}$ replicates of defatted ground milk thistle seed were extracted with $90 \mathrm{~mL}$ of methanol using a Soxhlet extraction apparatus for $8 \mathrm{~h}$. Extracts were cooled and transferred to $100 \mathrm{~mL}$ volumetric flasks and diluted to volume with methanol. One milliliter aliquots were analyzed for flavonolignan concentration. This procedure was repeated with five $1 \mathrm{~g}$ replicates of ground milk thistle tablets.

Sonication procedure Five $150 \mathrm{mg}( \pm 10 \%)$ replicates of defatted ground milk thistle seed were extracted with $25 \mathrm{~mL}$ of methanol using a sonicating bath at $45{ }^{\circ} \mathrm{C}$ for $30 \mathrm{~min}$. Samples were cooled to room temperature and centrifuged at
$5000 \mathrm{rpm}$ for $5 \mathrm{~min}$, and a sample of the solution was analyzed for flavonolignan concentration. This was repeated with five $70 \mathrm{mg}( \pm 10 \%)$ replicates of ground milk thistle tablets.

\section{Method validation—reference solution preparation}

Individual $1000 \mu \mathrm{g} / \mathrm{mL}$ stock solutions of each standard were prepared by weighing $10 \mathrm{mg}$ of each standard into separate $10 \mathrm{~mL}$ volumetric flasks and diluted with methanol. Isosilybin A and isosilybin B stock solutions were diluted to $500 \mu \mathrm{g} / \mathrm{mL}$ working stock solutions prior to preparation of the calibration standards each day from the original stock solutions.

The solutions for the calibration curves were prepared using serial dilutions of the stock solutions with methanol. The nominal concentrations of each standard in the sevenpoint calibration curves are summarized in Table 2.

\section{Method validation-sample preparation}

Raw materials Milk thistle seeds were ground using a waterjacketed hammer mill or grinder to $<40$ mesh powder. Test samples $(200.0 \mathrm{mg}, \pm 5.0 \mathrm{mg})$ were weighed into a $50-\mathrm{mL}$ conical tube and $2.0 \mathrm{~mL}$ of $1.5 \% \mathrm{H}_{2} \mathrm{SO}_{4}$ was added. Samples

Table 2 Nominal concentrations of the individual flavonolignans in each of the calibration solutions

\begin{tabular}{lllllllll}
\hline Flavonolignan & \multicolumn{2}{l}{ Approximate concentration $(\mu \mathrm{g} / \mathrm{mL})$} & & & $\begin{array}{l}\text { Average correlation } \\
\text { coefficients }\left(r^{2}\right)\end{array}$ \\
\cline { 2 - 8 } & Lin 1 & Lin 2 & Lin 3 & Lin 4 & Lin 5 & Lin 6 & Lin 7 \\
\hline Silychristin & 150 & 100 & 75 & 50 & 15 & 5 & 1.5 & 0.9992 \\
Silydianin & 150 & 100 & 75 & 50 & 15 & 5 & 1.5 & 0.9994 \\
Silybin A & 150 & 100 & 75 & 50 & 15 & 5 & 1.5 & 0.9992 \\
Silybin B & 150 & 100 & 75 & 50 & 15 & 5 & 1.5 & 0.9994 \\
Isosilybin A & 75 & 50 & 35 & 20 & 7.5 & 2 & 0.75 & 0.9993 \\
Isosilybin B & 75 & 50 & 35 & 20 & 7.5 & 2 & 0.75 & 0.9991 \\
\hline
\end{tabular}


were vortexed for $30 \mathrm{~s}$ and placed in a $50{ }^{\circ} \mathrm{C}$ shaking water bath at $60 \mathrm{rpm}$ for $30 \mathrm{~min}$. After the samples were cooled to room temperature, they were centrifuged at $5000 \mathrm{rpm}$ for $5 \mathrm{~min}$. The pretreatment solution was decanted and $2 \mathrm{~mL}$ of rinse water was added. Samples were vortexed for $30 \mathrm{~s}$ and centrifuged at $5000 \mathrm{rpm}$ for $5 \mathrm{~min}$. The rinse solution was decanted to waste. Twenty-five milliliters of $100 \%$ methanol was added to each sample and vortexed for $30 \mathrm{~s}$. The flavonolignans were extracted for $30 \mathrm{~min}$ in a heated sonicating water bath at $45^{\circ} \mathrm{C}$. Samples were cooled to room temperature and centrifuged at $5000 \mathrm{rpm}$ for $5 \mathrm{~min}$. An aliquot of the extract was filtered using a $0.45-\mu \mathrm{m}$ Teflon filter in an HPLC vial and subjected to HPLC analysis.

Powdered extracts, capsules, and tablets The contents of the 20 capsules were emptied and combined in a conical tube. Weights of the contents and empty shells were obtained, and the average fill weight was recorded. Contents were mixed using a spatula to homogenize the samples. Twenty tablets/ caplets were combined, weighed, and ground using a coffee grinder. Test material $(100.0 \mathrm{mg}, \pm 5.0 \mathrm{mg})$ was weighed into a $50-\mathrm{mL}$ conical tube and $25 \mathrm{~mL}$ of methanol was added using a volumetric pipet. The samples were vortexed and extracted in a heated sonicating water bath at $45^{\circ} \mathrm{C}$ for $30 \mathrm{~min}$. Samples were cooled to room temperature and centrifuged at $5000 \mathrm{rpm}$ for $5 \mathrm{~min}$.

Samples which are outside the calibration range were diluted either $1: 5$ or 1:10 with methanol prior to filtration. The dilution factors for each sample are summarized in Table 1. All samples were filtered using $0.45 \mu \mathrm{m}$ Teflon filters into HPLC vials and analyzed by HPLC.

Tinctures Tinctures were mixed thoroughly by inversion and diluted 1:2 or 1:5 with methanol and vortexed for $30 \mathrm{~s}$. The dilution factors for each sample are summarized in Table 1. The diluted samples were filtered using a $0.45-\mu \mathrm{m}$ Teflon filter into an HPLC vial and analyzed by HPLC. Note: Dilution of at least 1:2 is required as the high water content in tinctures causes solubility issues during filtration.

\section{Method validation}

The above method was validated according to AOAC International guidelines for conducting single-laboratory validation [26].

Limits of detection (LOD) and quantitation (LOQ) Suitable matrix blank was not available; therefore, the use of the International Union for Pure and Applied Chemistry method for determination of detection limits was not possible. The LOD for each analyte was determined using the US
Environmental Protection Agency Method Detection Limit (MDL) protocol [28]. The MDL is defined as the minimum concentration of substance that can be measured and reported with $99 \%$ confidence that the analyte concentration is greater than zero. To ensure matrix effects are still present, the tincture MT-TN003 was diluted so that all flavonolignans were at a very low concentration. Seven replicates were injected and the calculation of the MDL was as follows:

$\mathrm{MDL}=s \times t_{(0.01, n-1)}$

Where $s$ is the sample standard deviation of the replicates and $\mathrm{t}_{(0.01, n-1)}$ is the $t$ statistic with $\alpha=0.01$ and $n-1$ degrees of freedom.

A second set of seven replicates were assessed by diluting the tincture to another low concentration. This was performed to ensure variance is consistent at the low concentrations and to confirm that the MDLs are valid.

The LOQ was calculated as 10 times the sample standard deviation of the results for the replicates used to determine the MDL.

Precision Twelve replicates were analyzed for each test sample. Four replicate samples of each material were prepared and analyzed on three separate days. The within-day, betweenday, and total standard deviation values were calculated for each of the individual flavonolignans. The HorRat value for each flavonolignan in each material was also calculated to assess the overall precision of the method as described by Horwitz [29].

Accuracy One hundred milligrams of negative control material, composed of $99 \%$ maltodextrin and $1 \%$ magnesium stearate, was spiked with reference standards to contain total flavonolignan contents of 1.5, 5.0, and $11.8 \% \mathrm{w} / \mathrm{w}$ and diluted to a total volume of $25 \mathrm{~mL}$ with methanol, followed by sonication for $30 \mathrm{~min}$ at $45^{\circ} \mathrm{C}$. Samples were prepared in triplicate on three separate days and subjected to HPLC analysis.

Stability of standards Flavonolignan stability was assessed by preparing a stock solution containing $100 \mathrm{ppm}$ of each flavonolignans in methanol and was stored at room temperature for $72 \mathrm{~h}$. Aliquots of the solution were analyzed in triplicate at the time points $0,8,24,48$, and $72 \mathrm{~h}$. Peak areas were compared to time zero and deviations less than $5 \%$ were considered acceptable.

\section{Data analysis}

Individual flavonolignans from solid samples were quantified in $\%(w / w)$ and liquid samples were quantified in $\mu \mathrm{g} / \mathrm{mL}$ using external calibration. Microsoft Excel was used for calculations and statistical analyses. Optimization data was evaluated with 
single-factor analysis of variance (ANOVA) to determine whether statistically significant differences exist between data sets. Where appropriate, Tukey's Honestly Significant Difference (HSD) post hoc test was used to establish the significance of results. HorRat values were also calculated using Microsoft excel. The calculations used to determine the Horwitz ratio (HorRat), a normalized performance parameter used to evaluate overall method precision, are provided below:

$\mathrm{RSD}_{\mathrm{r}}($ found, $\%): \mathrm{RSD}_{\mathrm{r}}=\frac{\mathrm{SD}(\mathrm{R})}{\text { mean }} \times 100$

Where $\mathrm{SD}(\mathrm{r})$ is the population $\mathrm{SD}(\sigma / n$, where $\sigma$ is the sum of squares and $n$ is the number of replicates).

$\operatorname{PRSD}_{\mathrm{r}}\left(\mathrm{RSD}_{\mathrm{r}}\right.$ calculated, \% $): \mathrm{PRSD}_{\mathrm{r}}=2 \mathrm{C}^{-0.15}$

Where $\mathrm{C}$ is the concentration of the analyte expressed as a mass fraction.

HorRat value : HorRat $\frac{\mathrm{RSD}_{\mathrm{r}}}{\mathrm{PRSD}_{\mathrm{r}}}$

\section{Results and discussion}

\section{Chromatographic optimization}

New technologies in column manufacture using core-shell packing allows for the development of faster and/or higher resolution separations without requiring new, higher pressure LC systems. Optimization of the HPLC separation of silymarins was evaluated using several columns including Kinetex ${ }^{\circledR} 2.6 \mu \mathrm{m}, 3.0 \times 100 \mathrm{~mm} \mathrm{C} 8, \mathrm{C} 18$, and XB-C18 core shell columns, where the XB-C18 column was chosen for further optimization. Using a mixture of the six flavonolignan standards, the separation was achieved in less than $25 \mathrm{~min}$ (results not shown). When used to analyze the commercial products and milk thistle seeds, it was evident that several minor components were co-eluting with the silychristin, silydianin, and silybin B peaks. The separation was increased to 46 min using the milk thistle tincture to optimize the resolution. The chromatograms of the standard mixture, the milk thistle seeds, and the tincture are shown in Fig. 2. Due to the complexity of natural products, including milk thistle extracts, baseline resolution is rarely possible for all major analytes. As previously observed, there are several minor isomers that coelute with silybin B with the same molecular weight and are not resolved in traditional HPLC methods [30]. Therefore, this method improves the separation of these minor components from the flavonolignans of interest. It was observed that with MS compatible solvents, silydianin has some peak fronting, which was improved using the shell core XB-C18 column compared to other columns [30].
The column used in this separation provided several benefits including a reduction in solvent consumption, increased resolution of the flavonolignans, and a shorter run time compared to the original INA method [15]. The low back pressure from this column permits this method to be used by quality control labs equipped with traditional HPLC systems. This provides significant cost savings in the separation alone when this method is incorporated into laboratories.

\section{Optimization studies}

Pretreatment Milk thistle seeds can contain as much as 26$31 \%$ fat, which interferes with flavonolignan extraction [15, $31,32]$. The traditional Soxhlet method involves long extraction times, high temperatures, large sample sizes, and high solvent consumption per sample, which are not suitable for fast routine methods. Pretreatment of milk thistle seeds with $1.5 \% \mathrm{H}_{2} \mathrm{SO}_{4}$ is a potential alternative to replace defatting and has been shown to improve yields in bulk extractions [33]. The dilute acid was thought to break the seed coat cells, allowing for efficient extraction of the phytochemicals, while not interfering with the chemical composition of the flavonolignans [33]. In this work, optimization procedures for quick, routine analysis were guided using statistical analysis based on the total silymarin levels.

The pretreatment studies evaluated the silymarin yields after hexane defatting, treatment with $1.5 \% \mathrm{H}_{2} \mathrm{SO}_{4}$, and an untreated control. These results are summarized in Fig. 3, confirming that a pretreatment step is necessary prior to the silymarin extraction. There are significant differences between the three pretreatment groups $\left(\mathrm{F}_{(2,12)}=103, p<0.001\right)$. A Tukey's HSD post hoc test demonstrated that the hexane pretreatment is significantly different from the control (non-pretreated) and acid pretreated samples with a $\mathrm{q}_{\mathrm{obs}}(15.2)$ and $(-3.98)>\mathrm{q}_{\text {crit }}$ (3.15). As the acid pretreatment uses more environmentally friendly reagents, less glassware, lab space, and equipment, it was further optimized. Several pre-treatment solutions were analyzed for by HPLC, confirming that the flavonolignans were not extracted during pre-treatment.

In previous work, the exposure time was $24 \mathrm{~h}$ for pretreatment [33]. This long pretreatment is not suitable for fast sample preparation, so the exposure time varied from 0.5 to $24 \mathrm{~h}$. As summarized in Table 3, there are significant differences between the 7 pretreatment times $\left(\mathrm{F}_{(6,14)}=24.6, p<0.001\right)$. Treatment times $(0.5,1,2$, and $4 \mathrm{~h})$ were found to be significantly higher than $24 \mathrm{~h}$, given that $\mathrm{q}_{\text {obs }}>\mathrm{q}_{\text {crit }}$ for all. The flavonolignan levels decreased over time when exposed to high temperature solvents; therefore, in order to reduce the exposure of the samples to heat, the 0.5 -h pre-treatment time was selected. No significant differences were observed for pretreatment or rinse volumes $\left(\mathrm{F}_{(3,8)}=1.02, p=0.434\right)$. Therefore, $2 \mathrm{~mL}$ was chosen to reduce solvent use. 


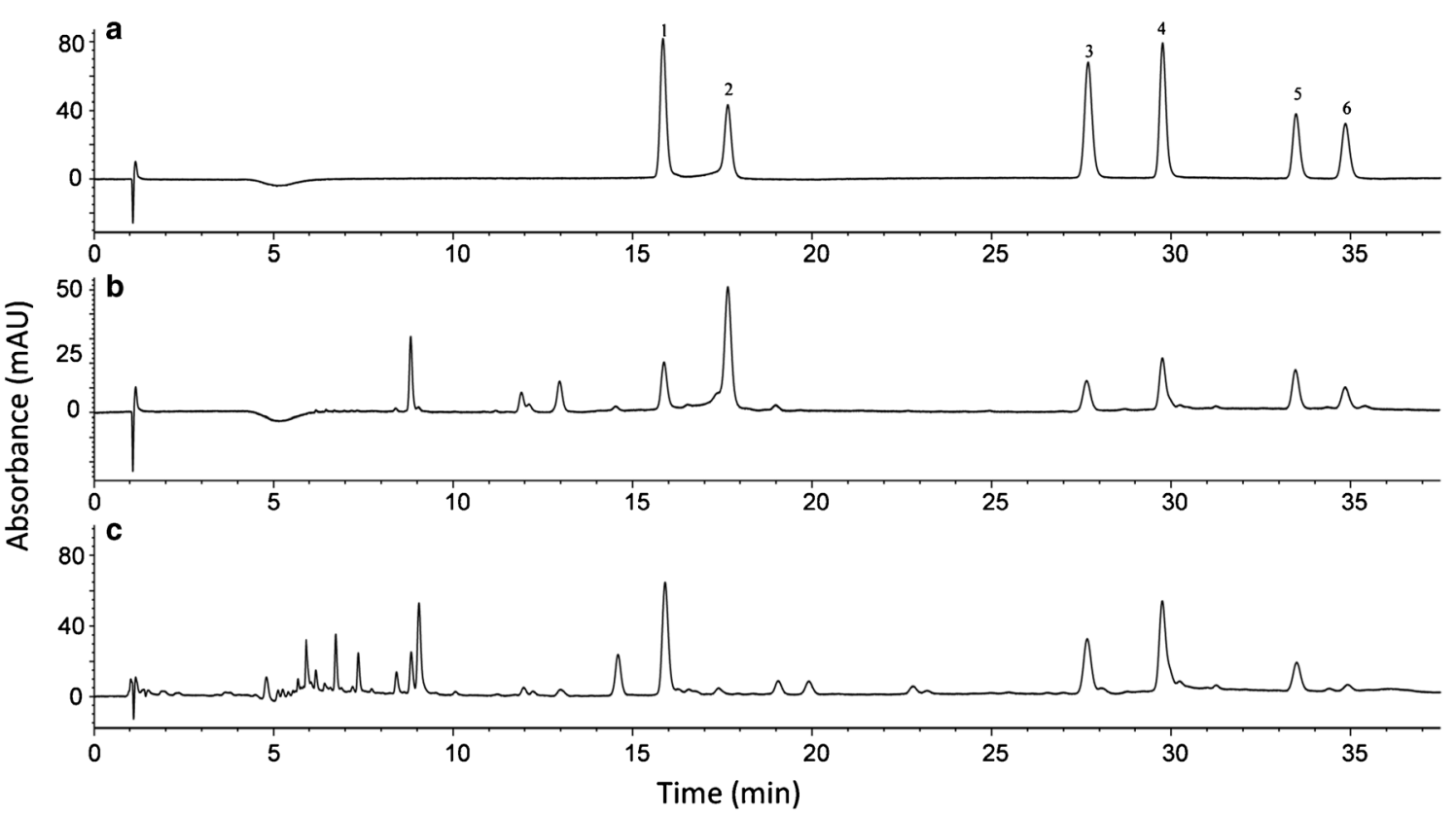

Fig. 2 HPLC separation and identification of flavonolignans in mixed flavonolignan reference standard (a), milk thistle seeds (b), and milk thistle tincture (c), all in methanol at $288 \mathrm{~nm}$

Extraction It is necessary to evaluate if sonication used in the pretreatment optimization is a comparable alternative to the industry standard Soxhlet extraction. The two extraction methods were compared using defatted milk thistle seed and a milk thistle tablet. The silymarin content in the seeds and tablet were significantly higher using sonication compared with Soxhlet $\left(\mathrm{F}_{(1,8)}=24.6, p<0.01 ; \mathrm{F}_{(1,8)}=12.0, p<0.01\right)$, as shown in Fig. 4. Both materials also resulted in lower variance using sonication. Therefore, sonication is a suitable alternative extraction method of the flavonolignans compared to Soxhlet extraction. When evaluating the individual flavonolignan contents, silydianin levels were lower with Soxhlet extraction. Silydianin levels decrease significantly when stored as tinctures at room temperature, indicating that it is possibly the least stable of the six major flavonolignans [34]. Sonication

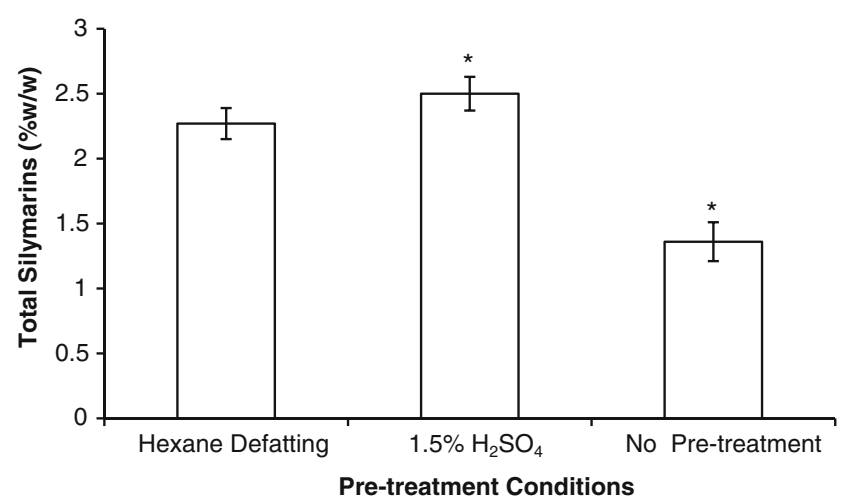

Fig. 3 Comparison of silymarin yield in milk thistle seeds after three different pre-treatment methods. Asterisk signifies significance $(p<0.05)$ from the hexane defatting pretreatment condition reduced the degradation of the flavonolignans and improved the determinations in milk thistle seeds and finished products.

\section{Single-laboratory validation}

Selectivity Due to the complex mixtures of components in milk thistle extracts, resolution of $>1.0$ was achieved for five of the major flavonolignans from interfering peaks. Silydianin contained a small co-eluting component at the front of the peak, for which resolution could not be improved; therefore, resolution of less than 1.0 was obtained for this peak in the test samples. There was no evidence of chromatographic interferences at $288 \mathrm{~nm}$ from other botanical sources in the multicomponent formulations such as schizandra berry, dandelion extract, or artichoke extract.

Linearity The calibration curves constructed throughout the optimization and validation studies were linear based on visual inspection. The correlation coefficients were above 0.998 , confirming the linearity of the analytical range for the individual flavonolignans.

Limits of detection and quantitation Variance checks showed that the method used was applicable for the analytes. The MDL and LOQ for each of the flavonolignans are reported in Table 4.

Precision The responses for all of the analytes in the test materials were above the methods limit of detection. The silydianin peak was below the limit of quantitation in two tincture products; therefore, it was reported solely as detected 
Table 3 Comparison of total silymarin content in milk thistle seeds after pretreatment exposure times from 0.5 to $24 \mathrm{~h}$ with $1.5 \%$ $\mathrm{H}_{2} \mathrm{SO}_{4}$

\begin{tabular}{llllll}
\hline Pretreatment time $(\mathrm{h})$ & Average $(\% w / w)$ & Standard deviation $(\% w / w)$ & ANOVA & HSD post \\
\cline { 3 - 5 } & & & Variance & $P$ value & \\
\hline 0.5 & 2.15 & 0.06 & 0.004 & $<0.001$ & $11.9^{\mathrm{a}}$ \\
1 & 2.13 & 0.09 & 0.008 & & $11.2^{\mathrm{a}}$ \\
2 & 2.05 & 0.07 & 0.005 & $9.01^{\mathrm{a}}$ \\
4 & 2.02 & 0.05 & 0.002 & $7.92^{\mathrm{a}}$ \\
6 & 1.84 & 0.05 & 0.003 & 2.59 \\
18 & 1.78 & 0.02 & 0.0003 & 0.90 \\
24 & 1.75 & 0.03 & 0.0008 & & - \\
\hline
\end{tabular}

${ }^{\text {a }}$ Significance at $\alpha=0.05$ compared with $24 \mathrm{~h}$ pretreatment time and no precision analysis was performed for silydianin in these products. The results from three separate days of analysis indicated that all of the analytes had adequate precision in all of the matrixes evaluated. The HorRat values for the raw materials ranged from 0.86 to 1.55 , dry finished products ranged from 0.27 to 1.48 , and liquid finished products ranged from 0.21 to 0.98 . These values are within the acceptable range stated by the AOAC SLV guidelines for dietary supplements [26]. The precision data for raw materials and dry finished products has been summarized in Table 5 and for liquid finished products in Table 6 .

Accuracy qNMR was used to confirm the purities provided by the suppliers for the flavonolignan standards. Five of the six standards were found to have residual solvents, with a purity of greater than $98 \%$ without considering the residual solvent amounts. The isosilybin B standard was contaminated with a small organic compound, where two NMR signals were observed in the spectrum. It was concluded that the mass percentage of this component would be low due to the low molecular weight of the contaminant, although the mole percentage of the contaminant was $11 \%$. Due to the high purities

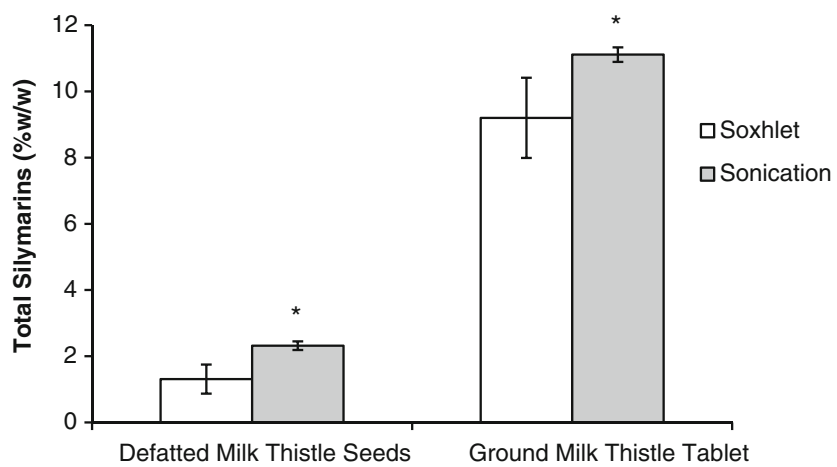

Fig. 4 Comparison of silymarin content $(\% w / w)$ in defatted milk thistle seeds and in ground milk thistle tablets using two extraction techniques: Soxhlet and sonication at $45{ }^{\circ} \mathrm{C}$. Asterisk signifies significance $(p<0.05)$ from the Soxhlet extraction technique observed in qNMR for the flavonolignans, the purities provided by the suppliers, ranging from $94-96 \%$ including residual solvent levels, were used for quantitation.

The silybin A/B mixed standard was assessed for purity in comparison to the individual silybin A and silybin B reference standards. The calculated purity of silybin A was $47.2 \%$ and for silybin B it was $50.2 \%$. The values obtained were slightly different in comparison with the suppliers' specifications of 47.0 and $52.6 \%$ respectively, although the total silybin content is similar ( $97.4 \%$ calculated versus $97.1 \%$ supplier specifications). The silybin $\mathrm{A} / \mathrm{B}$ mixture is a suitable alternative to be used in place of the individual reference standards silybin $A$ and $\mathrm{B}$.

The method accuracy was evaluated using a negative control spike recovery test at three concentration levels for all six flavonolignans. The spike concentrations ranged from 1.5 to $11.8 \% \mathrm{w} / \mathrm{w}$ total flavonolignans in order to cover the concentrations found in milk thistle seeds and capsules, while the individual flavonolignan ratios were similar to those found in milk thistle seeds. The results for recovery are summarized in Table 7, where the average ranged from 94.6 to $99.9 \%$.

Stability of standards Throughout the validation, samples were in queue for hours prior to injection; therefore, a mixture

Table 4 Method detection limit (MDL) and limit of quantitation (LOQ) calculated for each of the flavonolignans

\begin{tabular}{lll}
\hline Flavonolignan & MDL $(\mu \mathrm{g} / \mathrm{mL})$ & LOQ $(\mu \mathrm{g} / \mathrm{mL})$ \\
\hline Silychristin & 0.01 & 0.27 \\
Silydianin & 0.05 & 0.14 \\
Silybin A & 0.03 & 0.08 \\
Silybin B & 0.06 & 0.15 \\
Isosilybin A & 0.02 & 0.06 \\
Isosilybin B & 0.03 & 0.07 \\
\hline
\end{tabular}


Table 5 Precision results summary for milk thistle raw materials and dry finished products

\begin{tabular}{|c|c|c|c|c|}
\hline Matrix & Analyte & Mean $(\% w / w)$ & HorRat & RSD (\%) \\
\hline \multirow[t]{6}{*}{ MT-RM001 } & Silychristin & 0.26 & 1.05 & 5.17 \\
\hline & Silydianin & 1.04 & 1.32 & 5.23 \\
\hline & Silybin A & 0.20 & 1.10 & 5.58 \\
\hline & Silybin B & 0.30 & 1.35 & 6.49 \\
\hline & Isosilybin A & 0.21 & 1.07 & 5.41 \\
\hline & Isosilybin B & 0.14 & 0.93 & 4.96 \\
\hline \multirow[t]{6}{*}{ MT-RM002 } & Silychristin & 0.37 & 1.00 & 4.65 \\
\hline & Silydianin & 1.07 & 1.55 & 6.13 \\
\hline & Silybin A & 0.29 & 1.13 & 5.44 \\
\hline & Silybin B & 0.45 & 1.15 & 5.21 \\
\hline & Isosilybin A & 0.25 & 1.05 & 5.19 \\
\hline & Isosilybin B & 0.16 & 0.86 & 4.56 \\
\hline \multirow[t]{6}{*}{ MT-BE001 } & Silychristin & 13.54 & 0.58 & 1.57 \\
\hline & Silydianin & 0.38 & 0.77 & 3.57 \\
\hline & Silybin A & 13.28 & 0.58 & 1.58 \\
\hline & Silybin B & 19.35 & 0.42 & 1.07 \\
\hline & Isosilybin A & 4.75 & 0.36 & 1.13 \\
\hline & Isosilybin B & 1.56 & 0.27 & 1.03 \\
\hline \multirow[t]{6}{*}{ MT-CР001 } & Silychristin & 4.80 & 0.86 & 2.71 \\
\hline & Silydianin & 2.33 & 1.48 & 5.21 \\
\hline & Silybin A & 3.56 & 1.07 & 3.52 \\
\hline & Silybin B & 5.46 & 0.84 & 2.59 \\
\hline & Isosilybin A & 2.01 & 0.71 & 2.56 \\
\hline & Isosilybin B & 0.89 & 0.84 & 3.44 \\
\hline \multirow[t]{6}{*}{ MT-CР002 } & Silychristin & 5.46 & 0.96 & 2.97 \\
\hline & Silydianin & 4.49 & 1.02 & 3.24 \\
\hline & Silybin A & 6.14 & 1.23 & 3.74 \\
\hline & Silybin B & 8.98 & 1.32 & 3.78 \\
\hline & Isosilybin A & 2.84 & 0.95 & 3.24 \\
\hline & Isosilybin B & 1.37 & 1.20 & 4.59 \\
\hline \multirow[t]{6}{*}{ МT-СР003 } & Silychristin & 6.51 & 0.45 & 1.35 \\
\hline & Silydianin & 9.85 & 0.60 & 1.70 \\
\hline & Silybin A & 6.61 & 0.57 & 1.72 \\
\hline & Silybin B & 10.17 & 0.68 & 1.92 \\
\hline & Isosilybin A & 4.07 & 0.65 & 2.10 \\
\hline & Isosilybin $\mathrm{B}$ & 2.23 & 0.58 & 2.04 \\
\hline \multirow[t]{6}{*}{ MT-TB001 } & Silychristin & 0.33 & 0.44 & 2.09 \\
\hline & Silydianin & 0.09 & 1.31 & 7.56 \\
\hline & Silybin A & 0.31 & 0.33 & 1.59 \\
\hline & Silybin B & 0.47 & 0.47 & 2.13 \\
\hline & Isosilybin A & 0.14 & 0.34 & 1.83 \\
\hline & Isosilybin B & 0.06 & 0.84 & 5.19 \\
\hline \multirow[t]{6}{*}{ MT-ТВ002 } & Silychristin & 2.45 & 0.43 & 1.51 \\
\hline & Silydianin & 2.09 & 0.35 & 1.26 \\
\hline & Silybin A & 2.35 & 0.4 & 1.41 \\
\hline & Silybin B & 3.56 & 0.87 & 2.86 \\
\hline & Isosilybin A & 1.22 & 0.44 & 1.72 \\
\hline & Isosilybin B & 0.61 & 1.20 & 5.15 \\
\hline
\end{tabular}

of flavonolignan standards in methanol was stored at room temperature for $72 \mathrm{~h}$ to confirm flavonolignan stability. Based on the minimal changes in peak area $(<2 \%)$ from the initial injections, no degradation of the flavonolignans occurred. It is recommended that stock solutions be stored at $-20{ }^{\circ} \mathrm{C}$ when not in use, as no long-term storage analysis was performed at higher temperatures.
Table 6 Precision results summary for milk thistle liquid finished products

\begin{tabular}{lllll}
\hline Matrix & Analyte & Mean $(\mu \mathrm{g} / \mathrm{mL})$ & HorRat & RSD (\%) \\
\hline MT-TN001 & Silychristin & 356.5 & 0.35 & 2.32 \\
& Silydianin & detected & $\mathrm{n} / \mathrm{a}$ & $\mathrm{n} / \mathrm{a}$ \\
& Silybin A & 198.5 & 0.70 & 5.07 \\
& Silybin B & 286.3 & 0.49 & 3.34 \\
& Isosilybin A & 112.3 & 0.36 & 2.83 \\
& Isosilybin B & 28.8 & 0.33 & 3.20 \\
MT-TN002 & Silychristin & 7.64 & 0.84 & 9.85 \\
& Silydianin & detected & $\mathrm{n} / \mathrm{a}$ & $\mathrm{n} / \mathrm{a}$ \\
& Silybin A & 7.88 & 0.84 & 9.88 \\
& Silybin B & 10.60 & 0.65 & 7.28 \\
& Isosilybin A & 5.75 & 0.31 & 3.80 \\
& Isosilybin B & 4.29 & 0.45 & 5.75 \\
MT-TN003 & Silychristin & 367.8 & 0.21 & 1.39 \\
& Silydianin & 180.4 & 1.00 & 7.31 \\
& Silybin A & 255.6 & 0.87 & 6.04 \\
& Silybin B & 407.3 & 0.44 & 2.84 \\
& Isosilybin A & 219.7 & 0.46 & 3.28 \\
& Isosilybin B & 139.9 & 0.35 & 2.66 \\
\hline
\end{tabular}

\section{Conclusions}

The INA method for flavonolignan quantitation recommended by the AOAC ERP underwent significant redevelopment and optimization according to statistically guided optimization procedures. The optimized method used a simple and fast

Table 7 Negative control spike recovery results for individual flavonolignans at three spike concentrations

\begin{tabular}{|c|c|c|c|c|}
\hline Standard & $\begin{array}{l}\text { Spiked } \\
\text { concentration (ppm) }\end{array}$ & $\begin{array}{l}\text { Recovery } \\
(\%)\end{array}$ & $\begin{array}{l}\text { RSD } \\
(\%)\end{array}$ & $\begin{array}{l}\text { Average } \\
\text { recovery (\%) }\end{array}$ \\
\hline \multirow[t]{3}{*}{ Silychristin } & 10 & 90.3 & 2.96 & \multirow[t]{3}{*}{94.6} \\
\hline & 35 & 99.3 & 2.33 & \\
\hline & 90 & 94.0 & 1.57 & \\
\hline \multirow[t]{3}{*}{ Silydianin } & 5 & 92.5 & 3.54 & \multirow[t]{3}{*}{95.8} \\
\hline & 50 & 97.9 & 1.95 & \\
\hline & 90 & 97.0 & 1.10 & \\
\hline \multirow[t]{3}{*}{ Silybin A } & 10 & 90.2 & 1.26 & \multirow[t]{3}{*}{95.6} \\
\hline & 30 & 99.2 & 2.64 & \\
\hline & 90 & 97.4 & 2.19 & \\
\hline \multirow[t]{3}{*}{ Silybin B } & 25 & 98.3 & 2.75 & \multirow[t]{3}{*}{97.5} \\
\hline & 50 & 98.2 & 3.53 & \\
\hline & 120 & 96.1 & 2.72 & \\
\hline \multirow{3}{*}{$\begin{array}{l}\text { Isosilybin } \\
\text { A }\end{array}$} & 5 & 95.6 & 3.85 & \multirow[t]{3}{*}{95.9} \\
\hline & 25 & 94.6 & 3.14 & \\
\hline & 50 & 97.3 & 2.64 & \\
\hline \multirow{3}{*}{$\begin{array}{l}\text { Isosilybin } \\
\text { B }\end{array}$} & 5 & 101.8 & 11.85 & \multirow[t]{3}{*}{99.9} \\
\hline & 10 & 95.4 & 8.60 & \\
\hline & 30 & 102.5 & 4.97 & \\
\hline
\end{tabular}


sample preparation procedure and was comparable to the original method. The method was subjected to a single-laboratory validation according to AOAC International SLV guidelines for milk thistle raw materials, bulk extracts, dry finished products, and tinctures. All of the parameters investigated were found to be within compliance with the guidelines. Therefore, this method is suitable for determining the concentration of the 6 main flavonolignans silychristin, silydianin, silybin A, silybin $\mathrm{B}$, isosilybin $\mathrm{A}$, and isosilybin $\mathrm{B}$ in single component milk thistle preparations or in combination with dandelion, schizandra berry, and/or artichoke extract. It is recommended that this method be adopted as Official First Action method status by AOAC International.

Acknowledgments We would like to thank Dr. Paul Shipley for his assistance in carrying out the quantitative NMR analysis. We would also like to acknowledge and thank Dr. Daise Lopes-Lutz and Yordanos Asmelash for their assistance in this project. Funding for this research was provided in part from the Advanced Foods and Materials Network (AFMNet), Alberta Innovates-BioSolutions, and the Growing Forward Program, a joint venture between the B.C. Ministry of Agriculture and Agriculture and Agri-Food Canada. Andreas Schieber and Paula Brown acknowledge funding from the Canada Research Chairs Program. Through partnership with Chromadex Inc., Paula Brown acknowledges funding support from the Office of Dietary Supplements, National Institutes of Health

Open Access This article is distributed under the terms of the Creative Commons Attribution 4.0 International License (http:// creativecommons.org/licenses/by/4.0/), which permits unrestricted use, distribution, and reproduction in any medium, provided you give appropriate credit to the original author(s) and the source, provide a link to the Creative Commons license, and indicate if changes were made.

\section{References}

1. Blumenthal M, Ferrier G, Cavaliere C (2006) HerbalGram 71:64 66

2. Blumenthal M, Lindstrom A, Lynch ME, Rea P (2011) HerbalGram 90:64-67

3. Cheung CWY, Gibbons N, Johnson DW, Nicol DL (2010) Anticancer Agents Med Chem 10:186-195

4. Davis-Searles PR, Nakanishi Y, Kim NC, Graf TN, Oberlies NH, Wani MC, Wall ME, Agarwal R, Kroll DJ (2005) Cancer Res 65: 4448-4457

5. Deep G, Agarwal R (2007) Integr Cancer Ther 6:130-145

6. Flora K, Hahn M, Rosen H, Benner K (1998) Am J Gastroenterol 93:139-143

7. Greenlee H, Abascal K, Yarnell E, Ladas E (2007) Integr Cancer Ther 6:158-165
8. Huseini HF, Larijani B, Heshmat R, Fakhrzadeh H, Radjabipour B, Toliat T, Raza M (2006) Phytother Res 20:1036-1039

9. Loguercio C, Festi D (2011) World J Gastroenterol 17:2288-2301

10. Post-White J, Ladas EJ, Kelly KM (2007) Integr Cancer Ther 6: 104-109

11. Raza SS, Khan MM, Ashafaq M, Ahmad A, Khuwaja G, Khan A, Siddiqui MS, Safhi MM, Islam F (2011) J Neurol Sci 309:45-54

12. Javed S, Kohli K, Ali M (2011) Alternat Med Rev 16:239-249

13. Kidd P, Head K (2005) Alternat Med Rev 10:193-203

14. Ding T, Tian S, Zhang Z, Gu D, Chen Y, Shi Y, Sun Z (2001) J Pharm Biomed Anal 26:155-161

15. NSF International (2004) Silymarins in Milk Thistle by HPLC INA Method 115.000 http://www.nsf.org/business/ina/milkthistle.asp. Accessed 18 Feb 2012

16. Quaglia MG, Bossù E, Donati E, Mazzanti G, Brandt A (1999) J Pharm Biomed Anal 19:435-442

17. Wang K, Zhang H, Shen L, Du Q, Li J (2010) J Pharm Biomed Anal 53:1053-1057

18. Ball KR, Kowdley KV (2005) J Clin Gastroenterol 39:520-528

19. Jacobs BP, Dennehy C, Ramirez G, Sapp J, Lawrence VA (2002) Am J Med 113:506-515

20. Mayer KÉ, Myers R, Lee S (2005) J Viral Hepat 12:559-567

21. Rambaldi A, Jacobs BP, Iaquinto G, Gluud C (2005) Am J Gastroenterol 100:2583-2591

22. Saller R, Brignoli R, Melzer J, Meier R (2008) Forsch Komplementmed 15:9-20

23. Tamayo C, Diamond S (2007) Integr Cancer Ther 6:146-157

24. Kroll DJ, Shaw HS, Oberlies NH (2007) Integr Cancer Ther 6:110 119

25. Rathbone R (2009) Written Report of FDA/NIH/AOAC Contract Number HHSF223200810042C. AOAC International. http://www. aoac.org/dietsupp6/ Dietary-Supplement-web-site/Final_Report August_28.pdf. Accessed 18 Feb 2012

26. AOAC International (2003) AOAC Guidelines for SingleLaboratory Validation of Chemical Methods for Dietary Supplements and Botanicals, Gaithersburg, MD www.aoac.org/ Official Methods/slv guidelines.pdf. Accessed 18 Feb 2012

27. Pauli GF, Jaki BU, Lankin DC (2005) J Nat Prod 68:133-149

28. Environmental Protection Agency (2002) Guidelines Establishing Test Procedures for the Analysis of Pollutants; Procedures for Detection and Quantification, 40 CFR pt. 146, Appendix D, rev. 1.11. http://ecfr. gpoaccess.gov/cgi/t/text/text-idx?c=ecfr\&sid=568 $757977 \mathrm{c} 9 \mathrm{~b} 563 \mathrm{bc} 6771 \mathrm{e} 3 \mathrm{f} 042 \mathrm{afe} 3 \mathrm{c} \& \mathrm{rgn}=$ div9\&view $=$ text\&node $=40: 23 \cdot 0 \cdot 1 \cdot 1 \cdot 1 \cdot 0 \cdot 1 \cdot 7.2 \&$ idno $=40$ Accessed 18 Feb 2012

29. Horwitz W (1982) Anal Chem 54:67A-76A

30. Kuki A, Nagy L, Deak G, Nagy M, Zsuga M, Keki S (2012) Chromatographia 75:175-180

31. Fathi-Achachlouei B, Azadmard-Damirchi S (2009) J Am Oil Chem Soc 86:643-649

32. Wallace SN, Carrier DJ, Clausen EC (2003) Appl Biochem Biotechnol 105-108:891-903

33. Subramaniam S, Vaughn K, Carrier DJ, Clausen EC (2008) Bioresour Technol 99:2501-2506

34. MacKinnon SL, Hodder M, Craft C, Simmons-Boyce J (2007) Planta Med 73:1214-1216 